\title{
Diet-related practices and BMI are associated with diet quality in older adults
}

\author{
Dara W Ford ${ }^{1, *}$, Terryl J Hartman ${ }^{2}$, Christopher Still ${ }^{3}$, Craig Wood ${ }^{3}$, Diane Mitchell ${ }^{1}$, \\ Pao Ying Hsiao', Regan Bailey ${ }^{4}$, Helen Smiciklas-Wright', Donna L Coffman ${ }^{5}$ and \\ Gordon L Jensen ${ }^{1}$ \\ 'Department of Nutritional Sciences, The Pennsylvania State University, 110 Chandlee Laboratory, University \\ Park, PA 16802, USA: ${ }^{2}$ Department of Epidemiology, Emory University, Atlanta, GA, USA: ${ }^{3}$ Center for Health \\ Research \& Obesity Institute, Geisinger Health System, Danville, PA, USA: ${ }^{4}$ Office of Dietary Supplements, \\ National Institutes of Health, Rockville, MD, USA: ${ }^{5}$ The Methodology Center, The Pennsylvania State University, \\ State College, PA, USA
}

Submitted 25 February 2013: Final revision received 20 May 2013: Accepted 29 May 2013: First published online 2 July 2013

\begin{abstract}
Objective: To assess the association of diet-related practices and BMI with diet quality in rural adults aged $\geq 74$ years.

Design: Cross-sectional. Dietary quality was assessed by the twenty-five-item Dietary Screening Tool (DST). Diet-related practices were self-reported. Multivariate linear regression models were used to analyse associations of DST scores with BMI and diet-related practices after controlling for gender, age, education, smoking and self- $v$. proxy reporting.

Setting: Geisinger Rural Aging Study (GRAS) in Pennsylvania, USA.

Subjects: A total of 4009 (1722 males, 2287 females; mean age 81.5 years) participants aged $\geq 74$ years.

Results: Individuals with BMI $<18.5 \mathrm{~kg} / \mathrm{m}^{2}$ had a significantly lower DST score (mean $55 \cdot 8,95 \%$ CI $52 \cdot 9,58 \cdot 7$ ) than those individuals with BMI $=18 \cdot 5-24 \cdot 9 \mathrm{~kg} / \mathrm{m}^{2}$ (mean $60 \cdot 7,95 \%$ CI $60 \cdot 1,61 \cdot 5 ; P=0 \cdot 001$ ). Older adults with higher, more favourable DST scores were significantly more likely to be food sufficient, report eating breakfast, have no chewing difficulties and report no decline in intake in the previous 6 months.

Conclusions: The DST may identify potential targets for improving diet quality in older adults including promotion of healthy BMI, breakfast consumption, improving dentition and identifying strategies to decrease concern about food sufficiency.
\end{abstract}

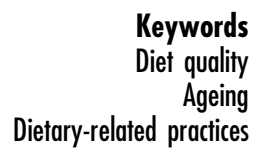

Diets consistent with dietary guidelines that are rich in fruits, vegetables, whole grains, low-fat dairy and lean meats are associated with decreased morbidity and mortality $^{(1)}$. Quality of diet becomes increasingly important in old age due to declining physiological function, changes in body composition and decreased energy requirements $^{(2,3)}$. Risk of undernutrition is also increased in older adults for some potentially modifiable reasons including financial constraints, appetite decline, poor dentition and functional and cognitive limitations ${ }^{(4)}$. The Dietary Screening Tool (DST) is a validated tool that utilizes foodbased questions developed for use in assessing diet quality in older, rural adults ${ }^{(5)}$. It is a simple, self-administered questionnaire containing food- and behaviour-related questions that assess overall dietary quality of older adults $^{(2)}$. The objective of the present study was to determine the relationship of the DST with diet-related practices and characteristics known to contribute to nutritional risk among a cohort of adults aged $\geq 74$ years.

\section{Materials and methods}

\section{Study participants}

The Geisinger Rural Aging Study (GRAS) began in 1994 with adults aged 65 years or older enrolled in a Medicaremanaged health maintenance organization. Study details have been published previously ${ }^{(6)}$. The participants have been followed as a longitudinal cohort over time with repeated measures of height, weight, medication use, diet-related practices, living environment, self-rated health and functional status. In-depth dietary assessment to estimate usual intakes has been conducted only on small subsets of the cohort in a cross-sectional manner and such data are not available for the entire cohort ${ }^{(5,7)}$.

All surviving GRAS participants ( $n$ 5993) were mailed demographic and health questionnaires and the DST for the current study in the autumn of 2009. After follow-up, 4009 (67\%) participants (1722 males, 2287 females; mean age 81.5 years) returned completed surveys, providing 
information on age, height, weight, smoking status, diet-related practices and dietary information, among other characteristics. Additionally, self-reporting or proxy reporting by someone other than the participant was noted. The study was conducted according to the guidelines laid down in the Declaration of Helsinki and all procedures involving human subjects/patients were approved by the Office of Research Protections at The Pennsylvania State University and the Human Research Protection Program of the Geisinger Health Systems Institutional Review Board. Consent was implied by survey completion.

\section{Dietary screening tool}

Detailed information on the development and validation of the DST has been described elsewhere ${ }^{(5,7)}$. The DST consists of twenty-five questions originally derived from extensive secondary analysis of the dietary intakes of rural older adults in the GRAS (see online supplementary material). The possible score range is from 0 to 100 points with 5 'bonus' points for multivitamin/mineral supplement use (score could not exceed 100). Responses to questions were then scored according to the previously validated scoring algorithm with a score $<60$ considered 'unhealthy', 60-75 considered 'borderline' and $>75$ considered 'healthy'(5). An example of a DST question is 'How often do you usually eat whole grain breads?' Participants then chose from 'never', 'less than once a week', ' 1 or 2 times a week' and ' 3 or more times a week' to classify their intake. Cognitive interviewing was used to ensure understandability of questions for the population of interest ${ }^{(7)}$. Points were allotted for each question based upon breakdown of major dietary components of the Healthy Eating Index-2005 ${ }^{(8)}$. Dietary quality was established by comparison with nutrient intakes ${ }^{(5,7)}$ and food group intakes ${ }^{(5)}$ derived from multiple $24 \mathrm{~h}$ recalls.

\section{Eating behaviour measures}

Nine total questions identified the presence of problems associated with diet-related practices through yes-or-no responses. All questions were self- or proxy reported. These questions addressed inadequate food or concerns about sufficient food, not eating on one or more days per month, having a decline in intake, eating alone, skipping breakfast, having more than one alcoholic drink per day for women or more than two per day for men, reporting chewing difficulty and mouth pain. Associations between all diet-related practices and DST score were analysed.

\section{Statistical analyses}

All data were analysed using the Statistical Analysis Software Package 9·3. Descriptive data were generated using PROC MEANS and PROC FREQ for all adults and by gender. Multivariate linear regression models were used to analyse associations of continuous DST score as the dependent variable with BMI and each of the nine diet-related practices after controlling for age (continuous), gender, education (<high school $v$. $\geq$ high school), smoking (ever/never) and self- $v$. proxy reporting. BMI was calculated from selfreported height and weight collected in the demographic and health questionnaires, and was assessed both as a continuous variable and categorically according to National Institutes of Health guidelines $\left(<18.5 \mathrm{~kg} / \mathrm{m}^{2}\right.$, $18 \cdot 5-24.9 \mathrm{~kg} / \mathrm{m}^{2}, 25 \cdot 0-29 \cdot 9 \mathrm{~kg} / \mathrm{m}^{2}$ and $\left.\geq 30 \cdot 0 \mathrm{~kg} / \mathrm{m}^{2}\right)$. All dietary behaviours that were related significantly to DST score at $P<0.05$ were retained as potential candidates for the multivariate model. Results are presented as mean DST scores with 95\% confidence intervals adjusted for age, gender, self- or proxy reporting, and BMI when BMI was not the independent variable of interest. $P$ values are for the tests of between-group differences from the multivariate models. Interactions between the predictors of interest (diet-related practices and BMI) and each covariate (gender, BMI, age, education, smoking, self- $v$. proxy reporting) were assessed by including each individual factor (e.g. gender) and its cross-product term in separate models. Significance was considered at $P<0 \cdot 05$.

\section{Results}

Descriptive characteristics of the sample are shown in Table 1. Compared with those who completed the DST, non-responders were older $(83.2 v$ v. $81 \cdot 4$ years; $P<0 \cdot 0001)$ and more likely to be female (OR $=1 \cdot 3,95 \%$ CI $1 \cdot 2,1 \cdot 5 ; P<0 \cdot 0001)$. Less than $9 \%$ ( $n$ 333) of participants used proxy reporters and those who did were more likely to be male $(\mathrm{OR}=1 \cdot 5,95 \%$ CI $1 \cdot 2,1 \cdot 9 ; P=0 \cdot 0002)$, less likely to report education beyond high school (OR $=0 \cdot 5,95 \% \mathrm{CI} 0 \cdot 3,0 \cdot 7 ; P=0 \cdot 0002$ ), older (mean $83 \cdot 7$ (SD 5.5) years $v .81 \cdot 2(\mathrm{sD} 4 \cdot 1)$ years; $P<0.0001)$ and had lower DST scores (mean 57.6 (sD 12.3) v. $60 \cdot 6$ (SD 12.7); $P<0 \cdot 0001)$. The cohort was comprised almost exclusively of non-Hispanic whites $(98 \cdot 7 \%)$ with at least a high school degree. Less than half the sample was male (43\%). BMI did not differ by gender. Although over half of the respondents lived with a spouse ( $n$ 2095), $46 \%$ of female respondents lived alone compared with only $20 \%$ of male respondents. The mean unadjusted DST score for the sample was $60 \cdot 3$ (SD 12.7), with females (mean 61.9 $(\mathrm{SD} 12 \cdot 6)$ ) reporting a significantly higher score than males (mean 58.2 (sD 12.4); $P<0 \cdot 0001$ ).

Participants who had $\mathrm{BMI}<18.5 \mathrm{~kg} / \mathrm{m}^{2}$ had significantly lower DST scores (OR $=55 \cdot 8,95 \%$ CI $52 \cdot 9$, $58 \cdot 7)$ than those participants with BMI $=18 \cdot 5-24 \cdot 9 \mathrm{~kg} / \mathrm{m}^{2}$ $(\mathrm{OR}=60 \cdot 8,95 \%$ CI 59.5, 60.9; $P=0 \cdot 001)$ after adjustment for age, sex, education, smoking status and self- $v$. proxy reporting. The adjusted DST score for those participants with $\mathrm{BMI}<18.5 \mathrm{~kg} / \mathrm{m}^{2}$ remained significantly lower $(\mathrm{OR}=55 \cdot 8,95 \% \mathrm{CI} 52 \cdot 9,58 \cdot 7)$ compared with the DST score for all other BMI classes combined $(\mathrm{OR}=60 \cdot 5$, $95 \%$ CI $60 \cdot 1,60 \cdot 9 ; P=0 \cdot 002)$. In contrast, compared with 
Table 1 Characteristics of study participants: rural adults aged $\geq 74$ years, Geisinger Rural Aging Study (GRAS), Pennsylvania, USA, autumn 2009

\begin{tabular}{|c|c|c|c|c|}
\hline \multirow[b]{2}{*}{ Characteristic } & \multicolumn{2}{|c|}{ Men $(n 1722 ; 43.0 \%)$} & \multicolumn{2}{|c|}{ Women ( $n 2287 ; 57 \cdot 0 \%)$} \\
\hline & Mean or $n$ & SE or $\%$ & Mean or $n$ & SE or $\%$ \\
\hline Age (years)* & $81 \cdot 3$ & $4 \cdot 2$ & $81 \cdot 5$ & $4 \cdot 4$ \\
\hline \multicolumn{5}{|l|}{ Race } \\
\hline White & 1654 & $98 \cdot 2$ & 2234 & $99 \cdot 1$ \\
\hline Non-Hispanic black & 29 & $1 \cdot 7$ & 15 & 0.7 \\
\hline Other & 1 & $0 \cdot 1$ & 4 & $0 \cdot 2$ \\
\hline \multicolumn{5}{|l|}{ Education } \\
\hline$<$ High school & 1327 & $77 \cdot 1$ & 1942 & $84 \cdot 9$ \\
\hline$\geq$ High school & 395 & $22 \cdot 9$ & 345 & $15 \cdot 1$ \\
\hline \multicolumn{5}{|l|}{ BMI $\left(\mathrm{kg} / \mathrm{m}^{2}\right)$} \\
\hline$<18 \cdot 5$ & 14 & $0 \cdot 8$ & 59 & $2 \cdot 6$ \\
\hline $18 \cdot 5-24 \cdot 9$ & 460 & $26 \cdot 7$ & 696 & $30 \cdot 4$ \\
\hline $25 \cdot 0-29 \cdot 9$ & 814 & $47 \cdot 3$ & 839 & $36 \cdot 7$ \\
\hline$\geq 30 \cdot 0$ & 434 & $25 \cdot 2$ & 693 & $30 \cdot 3$ \\
\hline \multicolumn{5}{|l|}{ Ever smoke } \\
\hline Yes & 61 & $3 \cdot 6$ & 82 & $3 \cdot 7$ \\
\hline No & 1629 & $96 \cdot 4$ & 2159 & $96 \cdot 3$ \\
\hline \multicolumn{5}{|l|}{ Eat breakfast } \\
\hline Yes & 1660 & $96 \cdot 4$ & 2190 & $95 \cdot 8$ \\
\hline No & 62 & $3 \cdot 6$ & 97 & $4 \cdot 2$ \\
\hline \multicolumn{5}{|l|}{ Eat alone } \\
\hline Yes & 305 & $17 \cdot 7$ & 851 & $37 \cdot 2$ \\
\hline No & 1417 & $82 \cdot 3$ & 1436 & $62 \cdot 8$ \\
\hline \multicolumn{5}{|l|}{ Intake decline } \\
\hline Yes & 111 & $6 \cdot 5$ & 161 & $7 \cdot 0$ \\
\hline No & 1611 & $93 \cdot 5$ & 2126 & $93 \cdot 0$ \\
\hline \multicolumn{5}{|l|}{ Excess alcohol } \\
\hline Yes & 94 & $5 \cdot 5$ & 37 & $1 \cdot 6$ \\
\hline No & 1628 & $94 \cdot 5$ & 2250 & $98 \cdot 4$ \\
\hline \multicolumn{5}{|l|}{ Food insufficient } \\
\hline Yes & 8 & $0 \cdot 5$ & 9 & $0 \cdot 4$ \\
\hline No & 1714 & $99 \cdot 5$ & 2278 & $99 \cdot 6$ \\
\hline \multicolumn{5}{|l|}{ Enough food each day } \\
\hline Yes & 1681 & $97 \cdot 6$ & 2254 & $98 \cdot 6$ \\
\hline No & 41 & $2 \cdot 4$ & 33 & $1 \cdot 4$ \\
\hline \multicolumn{5}{|l|}{ No food some days } \\
\hline Yes & 4 & $0 \cdot 2$ & 7 & $0 \cdot 3$ \\
\hline No & 1718 & $99 \cdot 8$ & 2280 & $99 \cdot 7$ \\
\hline \multicolumn{5}{|l|}{ Chewing difficulty } \\
\hline Yes & 69 & $4 \cdot 0$ & 87 & $3 \cdot 8$ \\
\hline No & 1653 & $96 \cdot 0$ & 2200 & $96 \cdot 2$ \\
\hline \multicolumn{5}{|l|}{ Mouth pain } \\
\hline Yes & 41 & $2 \cdot 4$ & 53 & $2 \cdot 3$ \\
\hline No & 1681 & $97 \cdot 6$ & 2234 & $97 \cdot 7$ \\
\hline DST score* & $58 \cdot 2$ & $12 \cdot 4$ & $61 \cdot 9$ & $12 \cdot 6$ \\
\hline \multicolumn{5}{|l|}{ DST category† } \\
\hline$<60$ & 917 & $53 \cdot 3$ & 925 & $40 \cdot 4$ \\
\hline $60-75$ & 629 & 36.5 & 976 & $42 \cdot 7$ \\
\hline$>75$ & 176 & $10 \cdot 2$ & 386 & $16 \cdot 9$ \\
\hline
\end{tabular}

DST, Dietary Screening Tool.

*These data are presented as mean and standard error; all other data are presented as number and percentage. tCategories utilized from previously published data ${ }^{(1)}$.

participants with BMI $=18 \cdot 5-24 \cdot 9 \mathrm{~kg} / \mathrm{m}^{2}$, there were no statistically significant differences in DST score for either overweight or obese individuals (see Table 2). There were also no significant associations between BMI and any of the diet-related practices.

Four of the nine diet-related practices were significantly associated with DST score after adjustment for BMI, age, sex, education, smoking status and self- $v$. proxy reporting (Table 2). Significantly lower DST scores were found in participants who reported a decline in intake over the previous 3 months, skipping breakfast, concern about having enough food and difficulty with chewing or swallowing. The remaining five diet-related practices were not significantly associated with DST score. No meaningful and significant effect modifications were observed between any variables tested (data not presented).

\section{Discussion}

It was our goal to investigate the associations between BMI, diet-related practices and diet quality in a population 
Table 2 Association between adjusted mean DST score, diet-related practices and BMI: rural adults aged $\geq 74$ years, Geisinger Rural Aging Study (GRAS), Pennsylvania, USA, autumn 2009

\begin{tabular}{lccc}
\hline Eating practice* & Adjusted mean DST score & $95 \% \mathrm{Cl}$ & $P$ valuet \\
\hline Skip breakfast & $51 \cdot 7$ & $49 \cdot 8,53 \cdot 7$ & $<0 \cdot 0001$ \\
Eat breakfast & $60 \cdot 8$ & $60 \cdot 4,61 \cdot 2$ & - \\
Eat alone & $60 \cdot 5$ & $59 \cdot 8,61 \cdot 3$ & $0 \cdot 71$ \\
Eat with others & $60 \cdot 4$ & $59 \cdot 9,60 \cdot 8$ & - \\
Intake decline & $56 \cdot 8$ & $55 \cdot 3,58 \cdot 3$ & $<0 \cdot 0001$ \\
No decline & $60 \cdot 7$ & $60 \cdot 3,61 \cdot 1$ & - \\
Excess alcohol & $58 \cdot 7$ & $56 \cdot 5,60 \cdot 9$ & $0 \cdot 12$ \\
No excess alcohol & $60 \cdot 5$ & $60 \cdot 1,60 \cdot 9$ & - \\
Food insufficient & $53 \cdot 9$ & $48 \cdot 0,59 \cdot 8$ & $0 \cdot 03$ \\
Food sufficient & $60 \cdot 4$ & $60 \cdot 0,60 \cdot 8$ & - \\
Not enough food each day & $58 \cdot 9$ & $56 \cdot 1,61 \cdot 8$ & $0 \cdot 32$ \\
Enough food each day & $60 \cdot 4$ & $60 \cdot 0,60 \cdot 8$ & - \\
No food some days & $57 \cdot 4$ & $49 \cdot 7,65 \cdot 1$ & $0 \cdot 44$ \\
Always have food & $60 \cdot 4$ & $60 \cdot 0,60 \cdot 8$ & - \\
Chewing difficulty & $58 \cdot 2$ & $56 \cdot 3,60 \cdot 2$ & $0 \cdot 03$ \\
No difficulty & 60.5 & $60 \cdot 1,60 \cdot 9$ & - \\
Mouth pain & $59 \cdot 8$ & $57 \cdot 2,62 \cdot 3$ & 0.63 \\
No mouth pain & $60 \cdot 4$ & $60 \cdot 0,60 \cdot 8$ & - \\
Underweight (BMI $\left.<18 \cdot 5 \mathrm{~kg} / \mathrm{m}^{2}\right) \ddagger$ & $55 \cdot 8$ & $52 \cdot 9,58 \cdot 7$ & $0 \cdot 001$ \\
Not underweight & 60.5 & $60 \cdot 1,60 \cdot 9$ & - \\
\hline
\end{tabular}

${ }^{*}$ Controlling for sex, BMI, age, smoking status, education and self- $v$. proxy reporting.

tRepresent differences between groups (appetite decline $v$. no decline, concern about food $v$. no concern, etc.) after adjustment for covariates. ‡Controlling for sex, age, smoking status, education and self- $v$. proxy reporting.

of adults aged $\geq 74$ years. There are limited data on dietary quality for large cohorts of older adults, particularly those living in rural areas. Our results indicate that a low DST score is associated with low BMI and poor diet-related practices including chewing difficulties, skipping breakfast, concerns of food sufficiency and decline in intake.

Older adults with low BMI had a much poorer diet quality than all other older adults, including those who were obese. Population studies suggest that risk of mortality is doubled in older adults who have a BMI $<18.5 \mathrm{~kg} / \mathrm{m}^{2}$ compared with $18.5-24.9 \mathrm{~kg} / \mathrm{m}^{2}$ independent of recent weight change ${ }^{(9,10)}$. The association between obesity and mortality in older adults is complex, with overweight and mild obesity being associated with reduced mortality in cohort studies of adults $\geq 65$ years old with follow-up periods ranging from 3 to 18 years ${ }^{(9-11)}$. In a prior investigation within a small subset of the GRAS cohort ( $n$ 179) we found that a low nutrient-dense diet was associated with increased odds of obesity ${ }^{(12)}$ and lower waist circumference was associated with a prudent dietary pattern $^{(7)}$. In the current study, an association between obesity and diet quality was not detected. Of note, no participants in our previous study had BMI $<18 \cdot 5 \mathrm{~kg} / \mathrm{m}^{2(12)}$.

Chewing difficulty, skipping breakfast, food insufficiency and decline in intake were associated with poor diet quality. Chewing difficulty is linked to many adverse clinical outcomes, including a variety of morbidities, hospitalization and earlier mortality, and has been shown to affect consistency and selection of food ${ }^{(4)}$. Skipping breakfast is associated with decreased nutrient intake, which may impact development and progression of chronic disease ${ }^{(13)}$. In a nationally representative sample of adults aged 60-90 years, those who were food-insufficient consumed significantly less energy, carbohydrate, protein, saturated fat, $\mathrm{Fe}$ and $\mathrm{Zn}$ among other micronutrients and were more likely to report poor self-rated health than their food-sufficient peers ${ }^{(14)}$. Decline in intake may lead to unintentional weight loss which is often indicative of underlying disease, and undernutrition in older adults is strongly associated with increased mortality ${ }^{(15,16)}$. The DST is able to identify these diet-related practices as targetable areas for improvement in diet quality and potentially other health outcomes in older adults.

A relatively high response rate (67\%) in an aged community-dwelling cohort is a major strength of this investigation. However, there are some notable limitations to address. The external validity of the DST remains to be determined in other races and geographic regions. The number of remaining underweight older adults was quite low, likely due to decreased survivorship in elderly individuals with a low $\mathrm{BMI}^{(9,10)}$. The screening questionnaires rely on self-report, making results subject to recall bias. Additionally, only information regarding age and sex was available for non-responders and so additional comparisons could not be made.

Previously the DST was administered in an out-patient clinic setting, requiring participants to visit their local medical clinic in order to complete the questionnaire ${ }^{(5)}$. Rural older adults experience many barriers to health care including but not limited to social isolation, lack of transportation and financial constraints ${ }^{(17)}$. By surveying rural adults in their own homes, we were able to find targetable areas for improvement of nutritional quality. Overall food consumption decreases with age and it becomes increasingly important for older adults to consume high-quality nutrient-dense foods to meet nutrient needs ${ }^{(18)}$. 
The diet-related practices found to be associated with DST score serve as potential targets for altering behaviour to promote nutrient and energy intakes sufficient to meet requirements. It should also be noted that the mean overall DST score was below optimal (mean $=60$ ) with $86 \%$ of participants scoring $\leq 75$ on the DST. According to previous studies, this indicates that $86 \%$ of this sample has either unhealthy or borderline diet quality, and so has room for improvement ${ }^{(5)}$.

\section{Conclusions}

Older adults are at increased susceptibility for malnutrition due to age-associated changes in metabolism and physiology ${ }^{(18)}$, and with the number of aged persons increasing rapidly in our population ${ }^{(19)}$ improving nutritional status is a priority. Low DST scores were associated with low BMI, being food insecure, recent decline in food intake, skipping breakfast and chewing difficulties. These associations may help to identify opportunities for anticipatory guidance and interventions for health-care professionals to promote improvement in diet quality.

\section{Acknowledgements}

Sources of funding: This work was supported by the US Department of Agriculture (grant \#1950-51530-010-02G). Conflicts of interest: The authors report no conflict of interest. Authors' contributions: T.J.H., G.L.J. and H.S.-W. contributed to the writing and editing of this paper. C.W. and D.L.C. assisted with statistical analysis. C.S., D.M., P.Y.H and R.B. provided editorial assistance in writing this paper.

\section{Supplementary material}

To view supplementary material for this article, please visit http://dx.doi.org/10.1017/S1368980013001729

\section{References}

1. Russell J, Flood V, Rochtchina E et al. (2012) Adherence to dietary guidelines and 15-year risk of all-cause mortality. $\mathrm{Br}$ J Nutr (Epublication ahead of print version).
2. Jensen GL \& McGee M \& Binkley J (2001) Nutrition in the elderly. Gastroenterol Clin North Am 30, 313-334.

3. Brownie S (2006) Why are elderly individuals at risk of nutritional deficiency? Int J Nurs Pract 12, 110-118.

4. Bailey R, Gueldner S, Ledikwe J et al. (2005) The oral health of older adults: an interdisciplinary mandate. J Gerontol Nurs 31, 11-17.

5. Bailey R, Miller PE, Mitchell DC et al. (2009) Dietary screening tool identifies nutritional risk in older adults. Am J Clin Nutr 90, 177-183.

6. Jensen GL, Kita K, Fish J et al. (1997) Nutrition risk screening characteristics of rural older persons: relation to functional limitations and health care charges. Am J Clin Nutr 66, 819-828.

7. Bailey RL, Mitchell DC, Miller CK et al. (2007) A dietary screening questionnaire identifies dietary patterns in older adults. J Nutr 137, 421-426.

8. Guenther PM, Krebs-Smith SM, Reedy J et al. (2008) Healthy Eating Index-2005. Alexandria, VA: Center for Nutrition Policy and Promotion.

9. Locher JL, Roth DL, Ritchie CS et al. (2007) Body mass index, weight loss, and mortality in community-dwelling older adults. J Gerontol A Biol Sci Med Sci 62, 1389-1392.

10. Takata Y, Ansai T, Soh I et al. (2007) Association between body mass index and mortality in an 80-year-old population. J Am Geriatr Soc 55, 913-917.

11. Stessman J, Jacobs JM, Ein-Mor E et al. (2009) Normal body mass index rather than obesity predicts greater mortality in elderly people: the Jerusalem longitudinal study. $J \mathrm{Am}$ Geriatr Soc 57, 2232-2238.

12. Ledikwe JH, Smiciklas-Wright H, Mitchell DC et al. (2004) Dietary patterns of rural older adults are associated with weight and nutritional status. J Am Geriatr Soc 52, 589-595.

13. Gollub EA \& Weddle DO (2004) Improvements in nutritional intake and quality of life among frail homebound older adults receiving home-delivered breakfast and lunch. J Am Diet Assoc 104, 1227-1235.

14. Lee JS \& Frongillo EA Jr (2001) Nutritional and health consequences are associated with food insecurity among US elderly persons. J Nutr 131, 1503-1509.

15. Chapman IM (2007) The anorexia of aging. Clin Geriatr Med 23, 735-756.

16. Miller SL \& Wolfe RR (2008) The danger of weight loss in the elderly. J Nutr Health Aging 12, 487-491.

17. Goins RT, Williams KA, Carter MW et al. (2005) Perceived barriers to health care access among rural older adults: a qualitative study. $J$ Rural Health 21, 206-213.

18. Drewnowski A \& Evans WJ (2001) Nutrition, physical activity, and quality of life in older adults. J Gerontol A Biol Sci Med Sci 56, Suppl. 2, 89-94.

19. Centers for Disease Control and Prevention (2003) Public health and aging: trends in aging - United States and worldwide. MMWR Morb Mortal Wkly Rep 52, issue 6, 101-106. 